Research Article

Journal of Extension Education

Vol. 31 No. 2, 2019

DOI:https://doi.org/10.26725/JEE.2019.2.31.6269-6273

\title{
Performance Effectiveness of Agro Service Centres in Kerala
}

\author{
Safna Vatakke Kandy Meethal ${ }^{1}$ and B. Seema ${ }^{2}$
}

\begin{abstract}
Agriculture is the back bone of Indian economy. Time bound high-quality agro services are essential for the growth of agriculture in our country. The present study was conducted among the beneficiary farmers Agro Service Centres in Kerala, during the year 2018-19. The sample of the study comprised 120 farmers from purposively selected 26 Agro Service Centres. Performance effectiveness of Agro Service Centres was measured in terms of Performance Effectiveness Index (PEI). Based on the analysis of data, it was found that 40 per cent of the farmers placed the ASCs into high category of Performance Effectiveness Index. Most of the farmers had placed the ASCs into high-performance effectiveness category in the dissemination of information and technology.
\end{abstract}

Keywords: Agro Service Centre, Performance effectiveness, Services delivery, Farmer's income, Kerala

\section{INTRODUCTION}

Agriculture plays an indispensable role in the Indian economy. More than fifty per cent of India's population finds their way of living through agriculture and allied activities. Even though Kerala is blessed with all natural resources, agriculture sector in Kerala exhibits an abrupt decline. This is mainly because our farmers are not able to purchase good quality seeds and other inputs in small quantity due to their higher prices. Also, they are not capable to buy equipment and machinery for farming activities and the farmers are suffering from different kinds of losses in their farming due to unavailability of clinical and diagnostic services from experts. Availability of time- bound high-quality agro services are essential for the growth of agriculture in our country.

Agro Service Centres (ASCs) are the "onestop-shops" offering timely services and inputs to the desired extent at reasonable rates in time in order to improve the economic viability of farming and standard of living of the farming community (Sidhu and Vatta, 2012). The success of agriculture depends on the availability of the right quantity of inputs and services at the right place in right time. Agro Service Centres facilitate the farmers to achieve these and thereby help to bridge the gap between farmers and the agriculture domain experts by providing need-based, diversified information and services to

1 PG. Scholar, and 2 Professor and Head, Department of Agricultural Extension, College of Agriculture, Vellayani, Thiruvananthapuram, Kerala- 695522

Received : 09-08-2019; Accepted : 30-08-2019 
farmers (GoK, 2016). This study will help in revising the modus operandi of Agro Service Centres and thereby act as an impetus for the establishment of more Agro Service Centres and productive functioning of the existing Agro Service Centres.

\section{METHODOLOGY}

Performance effectiveness is operationally defined as the ability of Agro Service Centres to achieve the predetermined goals and objectives in appropriate time and right quality. Performance effectiveness was measured on the basis of three components namely performance effectiveness of ASC in dissemination of information and technology, Performance of ASC in services delivery and performance effectiveness of ASC on farmer's income. Performance Effectiveness Index (PEI) was calculated for each component and later mean of these indices was found to obtain the performance effectiveness index as perceived by farmers.

Performance effectiveness of ASC in Information and Technology dissemination $\left(X_{1}\right)$ :The respondents were asked to give their opinion about the performance effectiveness of ASCs in information and technology dissemination on a three point continuum as good, average and below average with the scoring 3, 2, and 1 respectively.

Performance Effectiveness Index of this component i.e. PEI $\left(X_{1}\right)$ was measured using the formula

PEI $\left(X_{1}\right)=100-\left(\frac{X 1 \text { max }-x 1 i}{\text { Range }}\right) \times 100$

Where $\mathrm{X}_{1 \text { max }}$ is the maximum obtained value of
$X_{1}$

$X_{1 i}$ is the observed value of $X_{1}$

Range $=$ maximum obtained value of $X_{1}$ minimum obtained value of $X_{1}$

Performance of ASC in Services Delivery $\left(X_{2}\right)$ : The respondents were asked to give their response regarding the adequacy of different available services in ASCs on a three point continuum as adequate, moderate and not adequate with the scoring 3, 2 and 1 respectively.

Performance Effectiveness Index of this component i.e. PEI $\left(X_{2}\right)$ was measured using the formula

PEI $\left(X_{2}\right)=100-\left(\frac{X 2 \max -x 2 i}{\text { Range }}\right) \times 100$

Where $X_{2 \max }$ is the maximum obtained value of $\mathrm{X}_{2}$

$X_{2 \mathrm{i}}$ is the observed value of $X_{2}$

Range $=$ maximum obtained value of $\mathrm{X}_{2}$ minimum obtained value of $X_{2}$

Performance effectiveness of ASC on Farmer's income $\left(\mathrm{X}_{3}\right)$ :The respondents were asked to give their response regarding the perceived changes in their farming after utilizing the information and services from ASCs on a three point continuum as 'increase', 'no change' and 'decrease' with the scoring 3 , 2 and 1 respectively.

Performance Effectiveness Index of this component i.e. PEI $\left(X_{3}\right)$ was measured using the formula.

PEI $\left(X_{3}\right)=100-\left(\frac{X 3 \text { max }-x 3 i}{\text { Range }}\right) \times 100$ 
Where $X_{3 \max }$ is the maximum obtained value of $\mathrm{X}_{3}$

$X_{3 i}$ is the observed value of $X_{3}$

Range $=$ maximum obtained value $\mathrm{X}_{3^{-}}$ minimum obtained value of $X_{3}$.

Performance effectiveness index (PEI) of ASCs as perceived by farmers was calculated as the mean of the indices of the three components of $\mathrm{PEI}$ and it was calculated using the formula Performance Effectiveness Index as perceived by the farmer $(\mathrm{PEI})=$

$$
\frac{P E I(X 1)+P E I(X 2)+P E I(X 3)}{3}
$$

Frequency and percentage analysis was carried out to find the distribution of farmers based on their perception regarding the performance effectiveness of Agro Service Centres and the centres were classified into three categories namely low, medium and high based on the range of PEI as perceived by the farmers.

\section{FINDINGS AND DISCUSSION}

Agro Service Centers in Kerala were providing agricultural information, technologies and services to farmers through suitable disseminating systems. Considering the overall Performance Effectiveness Index of Agro Service Centres in Kerala, it was found that majority of the beneficiary farmers had placed the Agro Service Centres in high and medium performance category. The perception of farmers about the performance of Agro Service Centres in services delivery was low and for most of the farmers, the services of
Agro Service Centres have contributed to an increase in income from farming.

\section{Performance of Agro Service Centres (ASCs) as perceived by beneficiaries}

Table 1 shows the categorization of Agro Service Centres based on Performance Effectiveness Index as perceived by the farmers.

Table 1

\section{Categorization of Agro Service Centres based on Peformance Effectiveness Index as Perceived by the Farmers}

\begin{tabular}{|l|c|c|}
\hline Category & Frequency & Percentage \\
\hline Low (<33) & 26 & 21.66 \\
\hline $\begin{array}{l}\text { Medium (33- } \\
66)\end{array}$ & 46 & 38.34 \\
\hline High (>66) & 48 & 40 \\
\hline Mean & \multicolumn{2}{|c|}{55.88} \\
\hline $\begin{array}{l}\text { Total number } \\
\text { of farmers }\end{array}$ & \multicolumn{2}{|c|}{120} \\
\hline
\end{tabular}

From Table 1, it is found that 40 per cent of the farmers scored the ASCs into high category of performance followed by 38.34 per cent of the farmers scored the ASCs into medium category of performance. Over twenty per cent $(21.66 \%)$ of beneficiaries opined that the performance of ASC was low. Hence it is inferred from the result that based on the perception of farmers, the overall performance and service delivery mechanism of Agro Service Centres was satisfactory.

Performance Effectiveness of Agro Service Centres in the Dissemination of Information and Technology $\left(\mathrm{X}_{1}\right)$ 
Performance effectiveness of ASC in information and technology dissemination is defined as the performance of Agro Service Centre in the dissemination of information and technology for the welfare of farming community. Table 2 shows the categorization of Agro Service Centres based on its performance effectiveness in information and technology dissemination

Table 2

Categorization of Agro Service Centres

based on its Performance Effectiveness in Information and Technology Dissemination.

\begin{tabular}{|l|c|c|}
\hline Category & Frequency & Percentage \\
\hline Low (<33) & 23 & 19.17 \\
\hline $\begin{array}{l}\text { Medium (33- } \\
66)\end{array}$ & 41 & 34.16 \\
\hline High (>66) & 56 & 46.67 \\
\hline Mean & \multicolumn{2}{|c|}{60.31} \\
\hline $\begin{array}{l}\text { Total number of } \\
\text { farmers }\end{array}$ & \multicolumn{2}{|c|}{120} \\
\hline
\end{tabular}

According to majority of the respondents, the performance effectiveness of ASCs was found to be high in Kerala in the dissemination of information and technology. Around 46 per cent of surveyed beneficiary farmers scored the ASCs into high category of performance in delivering different agricultural information and technologies to farmers. The result implies the adequacy, reliability and timeliness of ASCs in disseminating the information and technology to the farmers.

\section{Performance of ASC in Services Delivery $\left(X_{2}\right)$}

Performance of ASC in services delivery is defined as the adequacy of different services of ASC to meet the requirements of farmers. Table 3 shows the categorization of Agro Service Centres based on its performance in services delivery.

\section{Table 3}

Categorization of ASC based on its Performance in Services Delivery.

\begin{tabular}{|l|c|c|}
\hline Category & Frequency & Percentage \\
\hline Low (<33) & 41 & 34.17 \\
\hline $\begin{array}{l}\text { Medium (33- } \\
\text { 66) }\end{array}$ & 68 & 56.67 \\
\hline High (>66) & 11 & 9.16 \\
\hline Mean & \multicolumn{2}{|c|}{41.94} \\
\hline $\begin{array}{l}\text { Total number of } \\
\text { farmers }\end{array}$ & \multicolumn{2}{|c|}{120} \\
\hline
\end{tabular}

Table 3 revealed that more than fifty per cent $(56.67 \%)$ of the beneficiaries had scored the ASCs into medium category of performance in services delivery followed by 34.17 per cent scored the ASCs into low category. Only 9.16 per cent of beneficiaries were satisfied with the performance of ASCs in services delivery and hence they scored ASCs into high performance category.

Hence it is clear from the above table that the performance of ASCs in services delivery has not yet been able to meet the current service needs of farmers. Lack of enough experience in handling the service delivery system of ASCs may be the reason for the poor performance of ASCs in services delivery. 


\section{Performance Effectiveness of Agro Service Centres on improving Farmers' Income $\left(\mathrm{X}_{3}\right)$}

Performance effectiveness of ASC on farmer s' income is defined as the perceived impact of the services of ASC in farming and in farmer's income. Table 4 shows the categorization of Agro Service Centres based on its performance effectiveness on farmer $\mathrm{s}^{\prime}$ income.

Table 4

Categorization of ASCs based on its

Performance Effectiveness on Farmers' Income

\begin{tabular}{|l|c|c|}
\hline Category & Frequency & Percentage \\
\hline Low (<33) & 19 & 15.83 \\
\hline $\begin{array}{l}\text { Medium (33- } \\
66)\end{array}$ & 28 & 23.34 \\
\hline High (>66) & 73 & 60.83 \\
\hline Mean & \multicolumn{2}{|c|}{65.41} \\
\hline $\begin{array}{l}\text { Total number of } \\
\text { farmers }\end{array}$ & \multicolumn{2}{|c|}{120} \\
\hline
\end{tabular}

From Table 4, it was found that majority (60.83\%) of the beneficiaries scored the ASCs into high category of performance effectiveness on farmer's income followed by 23.34 per cent scored the ASCs into medium category of performance and 15.83 per cent beneficiaries scored the ASCs into the low category of performance effectiveness on farmer's income. Hence it is clear from the above table that, for most of the farmers the services of Agro Service Centres have contributed to an increase in income from farming.

\section{CONCLUSION}

It can be concluded that considering the 26 Agro Service Centres brought under the purview of the study, 40 per cent of them were categorized in high performance group by the respondents and of the three indices, service delivery was identified as the least contributing factor to the performance effectiveness. This implies the need to strengthen the service delivery aspects of the Agro Service Centres in Kerala for enhancing its performance effectiveness in farming.

\section{REFERENCES}

GOK[Government of Kerala]. (2016). Report of evaluation study on agro service centres in Kerala. Directorate of agriculture development \& farmers' welfare, Thiruvananthapuram. pp112.

Sidhu R S, \& Vatta, K. (2012). Improving economic viability of farming: A study of cooperative agro machinery service centres in Punjab. Agricultural Economics Research Review. 25(1): 427-434. 